\title{
Specifying Cases for Technology Enhanced Learning in a Small and Medium Enterprise
}

\author{
Vladan Devedžić* \\ University of Belgrade \\ Jove Ilića 154 \\ 11000 Belgrade, Serbia \\ E-mail: devedzic@fon.rs
}

\section{Sonja Radenković}

University of Belgrade

Jove Ilića 154

11000 Belgrade, Serbia

E-mail: sonjafon@gmail.com

\section{Jelena Jovanović}

University of Belgrade

Jove Ilića 154

11000 Belgrade, Serbia

E-mail: jeljov@gmail.com

\author{
Viktor Pocajt \\ INI d.o.o \\ 11000 Belgrade \\ Serbia \\ E-mail: v.pocajt@ini-int.com \\ *Corresponding author
}

\begin{abstract}
This paper presents the process of identifying and describing cases for Technology Enhanced Learning (TEL) in a Small/Medium Enterprise (SME), as a part of an ongoing international TEL project. It proposes a template for describing TEL cases in an SME that collaborates with other organizations, notably with a university/research group. An example case description is used to illustrate the template proposed. In addition, the paper discusses how such a case is supported by specific TEL services on the Web.
\end{abstract}

Keywords: Application case, TEL case, SME, template.

Biographical notes: Vladan Devedžić is a Professor of Software Engineering at the University of Belgrade, Serbia. His major research interests in the area of technology-enhanced learning include intelligent Web-based tutoring and learning, and application of current Web technologies to education. 


\begin{abstract}
Sonja Radenković is a $\mathrm{PhD}$ candidate at the University of Belgrade, Serbia. Her major research interests in the area of technology-enhanced learning include intelligent Web-based assessment, and application of current Web technologies to workplace learning.

Jelena Jovanović is an Assistant Professor of Software Engineering at the University of Belgrade, Serbia. Her major research interests in the area of technology-enhanced learning include personal learning environments and application of current Web technologies to education.

Viktor Pocajt is an Associate Professor of Technology at the University of Belgrade, Serbia. His major research interests in the area of technologyenhanced learning include application of current Web technologies to workplace learning.
\end{abstract}

\title{
1. Introduction
}

IntelLEO stands for Intelligent Learning Extended Organization. It is also the title of an ongoing international TEL research project, being conducted within the $7^{\text {th }}$ Framework Programme (FP7) of the European Commission. The project has officially started in February 2009. The project objective is to develop services that support a temporal integration of two or more different business and educational communities and organizational cultures into a specific learning community, i.e. an IntelLEO (Stokić et al., 2008). For example, one or two companies from industry, a university, and a training institution may want to collaborate and share business and educational efforts through performing various vertical and horizontal learning and knowledge-building (LKB) activities (Jovanović et al., 2007).

An initial project step was to clearly specify TEL cases for an IntelLEO. This paper:

- $\quad$ proposes the template to present TEL cases in organizations; although devised as a part of the IntelLEO project, with minor adaptation the approach and the template can be applied in other projects related to organizational learning as well;

- $\quad$ illustrates and evaluates the template based on the experience acquired through applying them in practice to describe TEL cases for a specific IntelLEO (involving an SME and a university);

- describes a selected IntelLEO service that supports TEL cases in this specific IntelLEO.

\section{IntelLEO Core Services}

In order to support individual, collaborative, and organizational LKB activities, IntelLEO assumes a service-oriented approach/architecture (SOA) based on two kinds of services:

- $\quad$ services for efficient management of collaborative LKB activities and access to and supply of shared content (called LKB services); and

- $\quad$ services for harmonization of individual and organizational objectives (called harmonization services).

To support collaborative LKB activities in an IntelLEO, LKB services must be highly flexible, scalable, and easy to integrate in different ICT environments of different actors within an IntelLEO. The IntelLEO project intends to provide a number of services and enable using them in combination with existing Portfolio Software Solutions (PSS) 
and Learning (Content) Management Systems (L(C)MS). This way, the impact of the services on new ways of collaboration between industry and educational institutions can increase. Table 1 outlines several categories of these services.

Table 1. Collaborative LKB services

\begin{tabular}{|c|c|c|c|c|}
\hline Service type & Input/request & Output & Main functionality & $\begin{array}{l}\text { Specific } \\
\text { requirements }\end{array}$ \\
\hline $\begin{array}{l}\text { Content/ } \\
\text { Knowledge } \\
\text { Provision }\end{array}$ & $\begin{array}{l}\text { Request for } \\
\text { knowledge objects } \\
\text { (KOs) either by a } \\
\text { user or other } \\
\text { services, such as } \\
\text { the Learning Path } \\
\text { Creator service }\end{array}$ & $\begin{array}{l}\text { A ranked list of } \\
\text { "matching" KOs } \\
\text { relevant for specific } \\
\text { issue (e.g. } \\
\text { manufacturing } \\
\text { problem) and context }\end{array}$ & $\begin{array}{l}\text { Locate, retrieve and } \\
\text { make accessible } \\
\text { knowledge/content } \\
\text { objects based on the } \\
\text { given learning context }\end{array}$ & $\begin{array}{l}\text { Documents, Stored } \\
\text { user knowledge, } \\
\text { Distributed databases } \\
\text { with data from } \\
\text { processes or products } \\
\text { in the network, } \\
\text { Dynamic delivery, } \\
\text { Support for different } \\
\text { learning styles } \\
\text { Pro-activeness - } \\
\text { suggesting further } \\
\text { readings according to } \\
\text { the (automatically } \\
\text { updated) } \\
\text { learner/group model. }\end{array}$ \\
\hline $\begin{array}{l}\text { (Human) } \\
\text { Resource } \\
\text { Discovery }\end{array}$ & $\begin{array}{l}\text { Request for } \\
\text { specific expertise, } \\
\text { trainers, partners }\end{array}$ & $\begin{array}{l}\text { Appropriate and } \\
\text { available expert(s), } \\
\text { trainers, } \\
\text { partners for LKB } \\
\text { Pro-active resources } \\
\text { provision (without } \\
\text { request) }\end{array}$ & $\begin{array}{l}\text { Searching for expertise } \\
\text { to support LKB in an } \\
\text { IntelLEO, trainers and } \\
\text { partners, according to } \\
\text { the defined objectives } \\
\text { Checking a vailability }\end{array}$ & $\begin{array}{l}\text { Mobile users, } \\
\text { Already defined } \\
\text { groups, } \\
\text { Different discovery } \\
\text { approaches (see the } \\
\text { text to follow) } \\
\text { Link to human } \\
\text { management systems } \\
\text { in an IntelLEO }\end{array}$ \\
\hline $\begin{array}{l}\text { Learning } \\
\text { Group } \\
\text { Composition }\end{array}$ & $\begin{array}{l}\text { Request for an } \\
\text { optimal learning } \\
\text { group }\end{array}$ & $\begin{array}{l}\text { Optimal group } \\
\text { (structure, members } \\
\text { etc.) }\end{array}$ & $\begin{array}{l}\text { Proposes group based } \\
\text { on identified available } \\
\text { expertise, trainers and } \\
\text { partners, individual } \\
\text { learning paths and } \\
\text { IntelLEO objectives }\end{array}$ & IntelLEO rules etc. \\
\hline $\begin{array}{l}\text { Collaboratio } \\
\mathrm{n} \\
\text { Traceability }\end{array}$ & $\begin{array}{l}\text { Request for tracing } \\
\text { of the group LKB }\end{array}$ & $\begin{array}{l}\text { Info on the learning } \\
\text { process and the } \\
\text { current state of } \\
\text { groups and } \\
\text { collaboration, } \\
\text { Info to react on } \\
\text { certain events }\end{array}$ & $\begin{array}{l}\text { Tracing of LKB } \\
\text { collaboration: } \\
\text { - continuous } \\
\text { - event driven (event } \\
\text { identification) } \\
\text { Tracing of: Team } \\
\text { results } \\
\text { Content/course usage, } \\
\text { Learning styles, } \\
\text { Interaction (type, } \\
\text { frequency etc.) } \\
\text { Feedback services - } \\
\text { user may enrich } \\
\text { learning resources. } \\
\text { Mechanisms for context } \\
\text { capturing }\end{array}$ & $\begin{array}{l}\text { Specific requirements } \\
\text { regarding security, } \\
\text { IntelLEO specific } \\
\text { rules, IPR, privacy } \\
\text { Allowing different } \\
\text { levels of details } \\
\text { (abstraction) }\end{array}$ \\
\hline
\end{tabular}

Two types of harmonization services will be developed during the course of the project as shown in Table 2. Learning path generation/planning services will support the fact that learners with different backgrounds and belonging to different learning groups will not only need different learning resources, but will typically use different paths/sequences in consulting the resources. Learning path generation services will define 
needs/criteria for providing resources for a specific user/group, and learning resources discovery services will then discover the resources that best fit the needs. The learning path for a specific user can be built starting from an analysis of her/his cognitive and affective needs and objectives set for different contexts (Tuomi-Gröhn, \& Engeström, (2003) ). In addition, the ways the user planned to realize those objectives and the criteria defined to evaluate how well did she/he achieve her/his objectives, and the needs of the organization (defined via organization policy services) should be taken into account as well. All this can be acquired from the user's e-PSS.

Organization policy services support learning processes of individuals inside an organization by providing organization objectives and policy within the LKB activities in an IntelLEO. These services represent a type of bidirectional filtering functions for the learning contents and collaborative LKB, with respect to the organization's specific learning objectives and policy. They may filter the resources that may be combined in order to fit to the organizational policy. On the other hand, organization policy services select the most appropriate learning resources for the individuals of the IntelLEO (out of those provided by the learning path generation and learning resources discovery/provision services). They also support selection (filtering) of human resources for collaborative learning. To implement organization policy services, new methods and tools for the filtering process will be developed using semantic reasoning approaches to dynamically incorporate the needs and objectives of organizations in the learning process of individuals.

Table 2. Harmonization services

\begin{tabular}{|c|c|c|c|c|}
\hline Service type & Input/request & Output & Main functionality & $\begin{array}{l}\text { Specific } \\
\text { requirements }\end{array}$ \\
\hline $\begin{array}{l}\text { Learning } \\
\text { Path Creator }\end{array}$ & $\begin{array}{l}\text { Request for } \\
\text { learning path } \\
\text { for an } \\
\text { individual/grou } \\
\text { p to achieve } \\
\text { stated } \\
\text { objective(s) }\end{array}$ & $\begin{array}{l}\text { Proposed path } \\
\text { for } \\
\text { individual/group } \\
\text { consistent with } \\
\text { the stated } \\
\text { objective(s) (e.g. } \\
\text { gradual increase } \\
\text { w.r.t. the } \\
\text { cognitive } \\
\text { capabilities) }\end{array}$ & $\begin{array}{l}\text { Selection of the learning } \\
\text { sequence and most appropriate } \\
\text { criteria to provide resources in a } \\
\text { specific context (for specific } \\
\text { learner and/or group etc.) } \\
\text { Provision of knowledge on } \\
\text { learners/groups }\end{array}$ & $\begin{array}{l}\text { Link to human } \\
\text { management systems } \\
\text { in IntelLEO. } \\
\text { Knowledge on } \\
\text { learner/group } \\
\text { Works in } \\
\text { combination with } \\
\text { Learning resources } \\
\text { provision/discovery } \\
\text { services (see the text } \\
\text { above). }\end{array}$ \\
\hline $\begin{array}{l}\text { Organization } \\
\text { Policy }\end{array}$ & $\begin{array}{l}\text { Request for } \\
\text { organisation } \\
\text { rules, } \\
\text { objectives. } \\
\text { Request to filter } \\
\text { content }\end{array}$ & $\begin{array}{l}\text { Provision of } \\
\text { organisation } \\
\text { rules, and/or } \\
\text { objectives } \\
\text { relevant for } \\
\text { specific } \\
\text { content/context } \\
\text { Selected } \\
\text { content/context } \\
\text { according to the } \\
\text { organisation } \\
\text { policy }\end{array}$ & $\begin{array}{l}\text { Identification of rules and/or } \\
\text { objectives, which are relevant } \\
\text { for the specific content/context } \\
\text { Filtering from the set of } \\
\text { provided content/knowledge } \\
\text { those which fit with the rules, } \\
\text { objectives, strategies }\end{array}$ & $\begin{array}{l}\text { Services } \\
\text { interconnected with } \\
\text { the organisation } \\
\text { legacy system } \\
\text { containing } \\
\text { information on } \\
\text { companies rules, } \\
\text { dynamic updates of } \\
\text { rules, objectives }\end{array}$ \\
\hline
\end{tabular}

The real power of the IntelLEO framework comes through interrelation of services presented above. These services may "profit" from each other, thus leading to a 
higher responsiveness of the learning environment in an IntelLEO. The project will establish and explore several interrelations among the proposed services, such as:

- Services for collaboration traceability will provide information on the context of learning/collaboration. This information can be used by services for learning path creation to assure the content/knowledge that best suits the individual and/or group, as well as by organization policy services to provide appropriate rules/objectives.

- A learning path selected by learning path generation services will provide information for future human resource discovery and learning group composition. This can accommodate different collaboration patterns and different technical backgrounds of the collaborating people.

- Traceability services will provide information about collaboration patterns applied by different learning groups. It may reflect upon organizational policy services.

- Learning resources provision/discovery services will proactively support the learners, and will also trigger human resources discovery services to suggest the learners topics to discuss with some other learner(s).

- Organization policy services will provide rules for human resource discovery and learning group composition services.

E-portfolios and collaborative LKB services make a good combination when a learner can do something individually. They can keep track of the learner's activities and (possibly changing) objectives

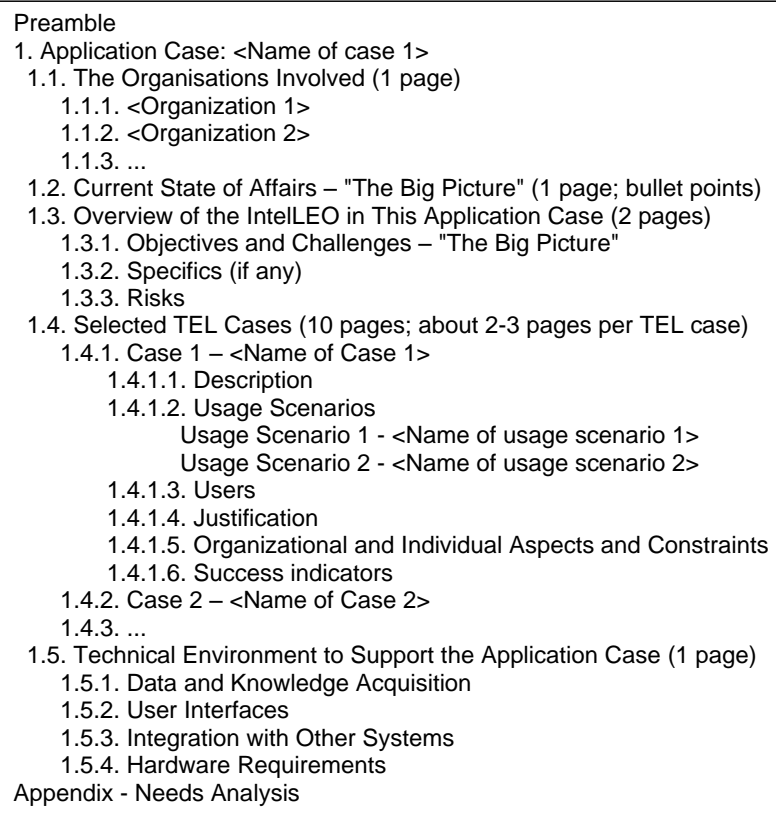

Figure 1. Template for presenting application and TEL cases 


\section{Template}

An application case is the term we use for a specific IntelLEO as a specific implementation of the general IntelLEO concept defined in the Introduction. The template adopted for presenting IntelLEO application cases (both in a corresponding project deliverable and elsewhere) is shown in Figure 1 (some details are omitted). It clearly separates high-level, informal, narrative descriptions from formal design specifications that rely on tech syntax (the latter are not covered in this paper). The only exception to this rule is the part describing the usage scenarios of specific TEL cases. It is included in the case presentations in order to make a "bridge" to formal technical specifications to follow at a later phase of the project. The template sections have obvious meanings and are illustrated in the next section.

\section{Example}

This example of how the template from Figure 1 can be used in describing an application case comes from an actual deliverable of the IntelLEO project. Of course, the descriptions presented are adapted to the format of this paper. The example describes only two TEL cases and only one of the usage scenarios for each case; in reality, there are many more. In addition, section 1.5 from the template shown in Figure 1 has been modified for this paper to describe a specific IntelLEO core service that supports the TEL cases.

\subsection{Application Case: INI / GOOD OLD AI}

\subsubsection{The Organizations Involved}

INI (http://www.ini-int.com/home.aspx), i.e. its branch from Belgrade, Serbia, a successful SME doing its business in the area of e-Engineering and e-Manufacturing.

The research partner is the GOOD OLD AI Lab (http://goodoldai.org) from the University of Belgrade, Serbia (GOOD OLD AI, for short). The lab members focus on research related to intelligent Web technologies, software engineering, and TEL systems and tools.

\subsubsection{Current State of Affairs - "The Big Picture"}

INI and GOOD OLD AI have already collaborated on other projects in the past, and some members of the two organizations knew each other already. The analysis of the INI work process and its LKB can be summarized as follows:

- both internal and external communication and exchange of information is mostly based on telephone and e-mail, which easily creates communication bottlenecks;

- $\quad$ subscription to information feed coming from relevant Web sites is limited;

- employees extend their knowledge through individual learning and by attending seminars, which is considered insufficient.

\subsubsection{Overview of the IntelLEO in This Application Case}

The major objectives and challenges include: 
- communication and exchange of information between INI and the GOOD OLD AI should greatly intensify and improve through the IntelLEO services;

- a centralized technical solution (a set of more advanced software tools) for exchange of information would produce better and more efficient results;

- additional subscription to information feed from relevant Web sites is welcome;

- increase of awareness of available relevant information on the Internet other than the one the metallurgists from INI are already aware of, as well as of awareness of new trends in the area, is considered highly beneficial in improving the work efficiency;

- more formal external communication and exchange of information is needed.

The rest of information from this subsection of the template are skipped in this example due to the space limitations.

\subsubsection{Selected TEL Cases}

Four collaborative TEL cases were identified through the required analysis of INI: learning about relevant R\&D trends (learning by INI employees, guided by GOOD OLD AI members), exploring new technologies (by selected INI employees, guided/supported by GOOD OLD AI members), specifying customer profiles (collaboratively), and supporting guided learning (planning, organizing, and supporting seminars for INI employees). As an illustration, some details about the first two cases are presented in the following subsections.

\subsubsection{Case 1 - Learning about Relevant R\&D Trends}

This TEL case is related to the INI's need to stay up-to-date with the latest research results and relevant technological developments that can be of interest for the company in terms of its constant focus on improving its products and remain the global leader in the field.

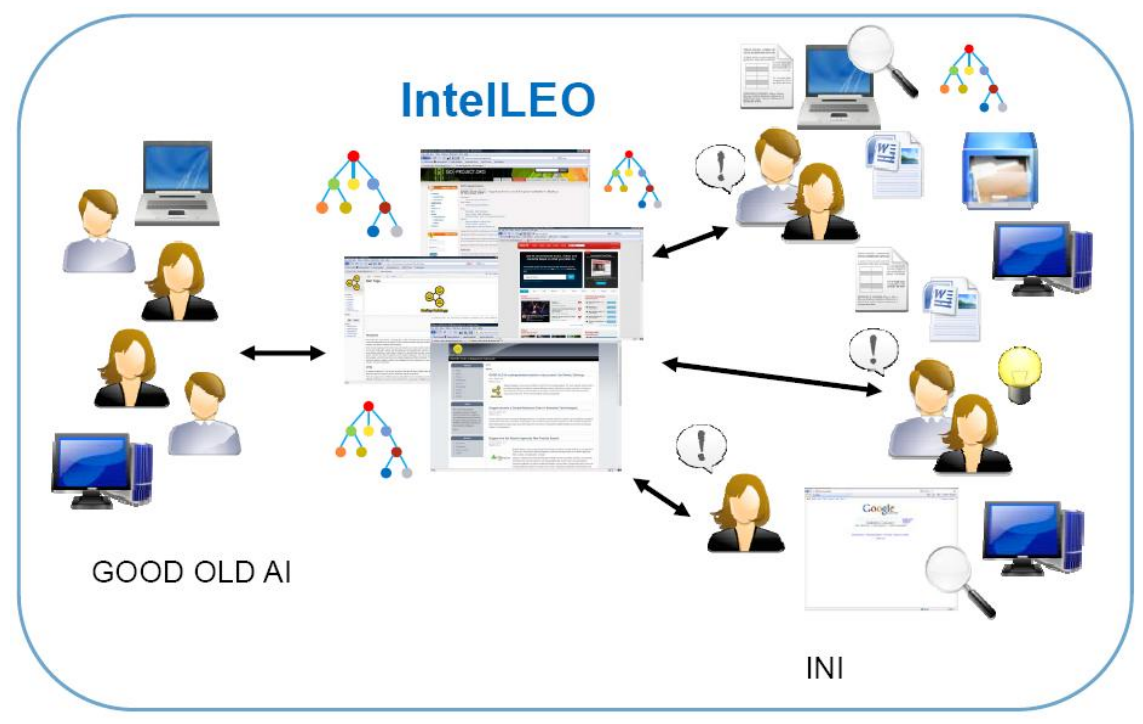

Figure 2. Learning about relevant R\&D trends 
In order to increase their awareness of available relevant R\&D information on the Internet, INI employees can consult the IntelLEO services as shown in Figure 2. The services should support their learning with transparent and seamless guidance provided by GOOD OLD AI researchers (socialization of tacit knowledge). For example, an INI employee may be interested in semantically annotating an electronic document relevant for a certain category of metals (e.g., a specific category of steel). By annotating the document, the employee can improve the navigation through the document for both the customers and the INI staff (harmonization with organization's needs). Researchers from the GOOD OLD AI Lab, being knowledgeable in the topic of semantic annotation, are already aware of relevant annotation tools and the corresponding learning resources and can upload the relevant information to the IntelLEO and/or guide the interested employee(s). As another example, an INI employee may want to consider subscribing to a relevant information feed. The IntelLEO services can provide RSS feeds from some of the relevant Web sources. The employee can suggest including feeds from other sites, or may work collaboratively with the GOOD OLD AI Lab researchers to search for and evaluate candidate feeds (collaboration activities). It is likely to expect that researchers other than the GOOD OLD AI Lab members will get involved over time, depending on their expertise.

Examples of usage scenarios envisioned in this TEL case include:

- discussion related to posted enquiries;

- manipulation of learning resources (insertion, removal, annotation, and evaluation of learning resources);

- interaction with information feeds (subscription, browsing, filtering, and archiving).

\subsubsection{Usage Scenario 1 - Manipulating Learning Resources}

Manipulating learning resources shown in Figure 3, is necessary for both parties involved this IntelLEO (GOOD OLD AI and INI), since it comes as a natural set of learning activities. Researcher and INI (i.e., an INI employee) can insert and remove a resource to/from the IntelLEO services (the Insert resource and Remove resource use cases), and it is up to INI to evaluate it (Evaluate resource). This evaluation is of interest to GOOD OLD AI, in terms of learning more about the real needs of organizational learning and getting a real-world feedback on the effectiveness of various learning tools and other resources. It is also of interest to INI in terms of indicating business actions to undertake accordingly. Both parties can view resources (the View resource use case), annotate them (Annotate resource) and view various statistics of using each specific resource (View resource statistics).

\subsubsection{Case 2 - Exploring New Technologies}

Selected employees from INI are encouraged to conduct research activities related to the company's business interests. These employees can use IntelLEO services for recommendations and guidance, playing an active role in terms of initiating researchrelated activities. Members of the GOOD OLD AI lab can exchange information with these employees, notify them of research events and news, write research papers with them collaboratively, and the like. 


\subsubsection{Usage scenario 1 - Learning about New Technology}

An INI employee (INI) who wants to learn about a specific technology should be able to find an expert researcher from the GOOD OLD AI Lab ${ }^{1}$ (Researcher) who can provide guidance related to this technology (Find expert) as shown in Figure 4. To a great extent, this can be supported by a combination of Human Resource Discovery, Learning Group Composition, and Organizational Policy core services.

Then INI can Post problem she/he wants to discuss and solve using the new technology. Post problem can sometimes include the use of Learning Path Creator service ("Learning about this issue I made these steps so far, but now I'm stuck. What should I do next?"). It can also be restricted in some cases, hence it should consult Organization Policy service.

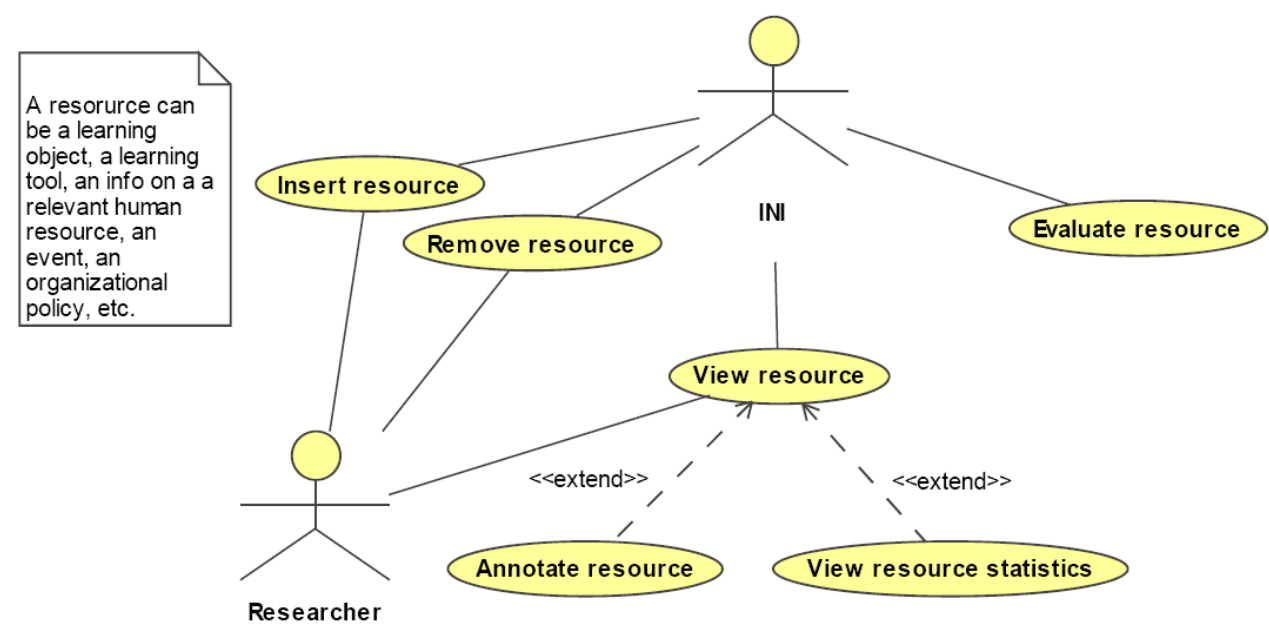

Figure 3. Usage scenario: Manipulating learning resources (notation used: use-case diagram, UML)

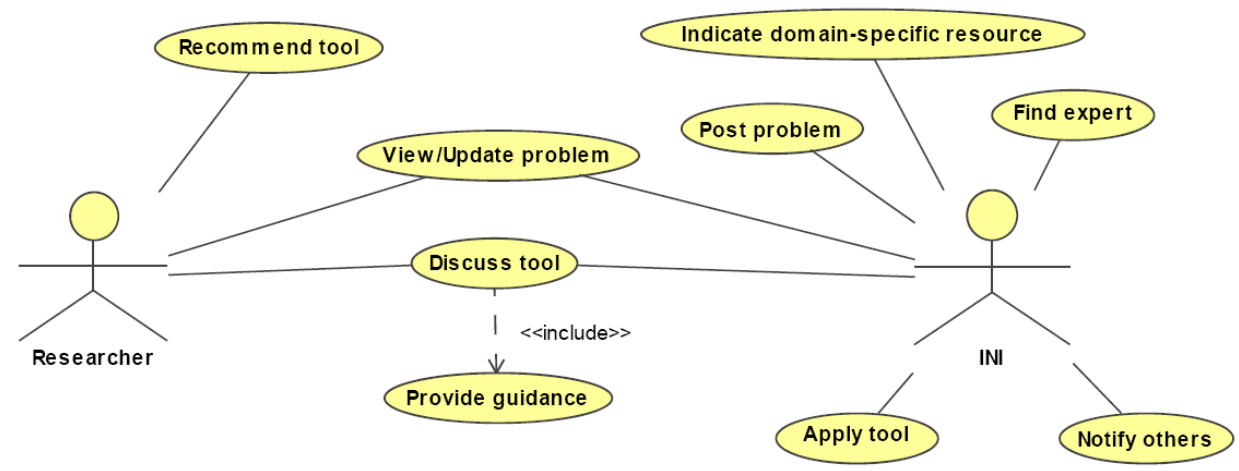

Figure 4. Usage scenario: Learning about new technology

${ }^{1}$ If applicable, Researcher can also be someone outside the GOOD OLD AI lab. 
If Researcher knows how to reply immediately, she/he may need to simply update the learning path that INI has already walked by suggesting new steps (again, using the Learning Path Creator service). However, it is more likely that Researcher will need to discuss the problem briefly in order to understand it properly (View/Update problem), and will possibly require some domain-specific clarifications. These, in turn, may include further discussion and use of Content/Knowledge Provision core service to access certain content. INI can Indicate domain-specific resource available through the shared repository of knowledge objects (KOs), in order for the Researcher to get familiarized with the problem better and possibly update INI's learning path. Researcher can then recommend one or more technologies/tools (Recommend tool) suitable for the problem (using Content/Knowledge provision and Learning Path Creation core services), and can Discuss tool and Provide guidance to INI in using the tool/technology. Note that various collaboration services can be used here if it turns necessary to extend the learning group, involve another expert, and so on.

During this process, INI can Apply tool in order to solve the specific problem, and Notify others in the company about it. A new learning group can be created now, this time involving more INI employees and the roles in the new group may be slightly different from the roles included in Post problem, Indicate domain-specific resource, and Recommend tool.

\section{Supporting TEL Cases by IntelLEO Core Services}

Section 4 has indicated how the usage scenarios described are supported by the IntelLEO core services shown in Tables 1 and 2 . In order to illustrate what these services really do in real-world cases, this section describes one of them - the Content/Knowledge Provision service - in detail, i.e. its design and implementation issues.

\subsection{Content/Knowledge Provision Service}

At different stages in the process of achieving specific competencies, learners in any learning organization need to get access to the required and relevant documents, KOs, or any other kind of resource they might need to successfully complete the necessary learning activities. Based on the requirements of a given learning context, the Content/Knowledge Provision service aims at locating, retrieving, and making appropriate learning objects (LOs) and KOs accessible to either members of an IntelLEO (i.e., end-users) or other IntelLEO services.

The Content/Knowledge Provision service enables learners to:

- access unstructured content that represent implicit organizational knowledge (reports, documents and notes related to a project, forum/blog posts, microblogging posts, discussion messages, Wiki entries) and "traditional" learning objects related to the domain knowledge of the task at hand;

- make structured, ontology-based annotations that describe learning and knowledge objects;

- perform semantic search for learning and knowledge objects needed to achieve the required competencies.

Figure 5 shows the typical context of using the Content/Knowledge Provision service and introduces its major components:

1. Unstructured content sources - the service annotates content from unstructured sources such as those mentioned above. 
2. Ontology management - this component provides the capability to access ontologies (Allemang \& Hendler, 2008) that are used in annotations to describe the content that is being annotated.

3. Annotation management - this component is responsible for providing the client application with a way to annotate unstructured (learning) content.

4. Client application - the client application uses the other components to provide the learner with an interface for accessing content and creating and querying annotations (i.e. IntelLEO CS and AS).

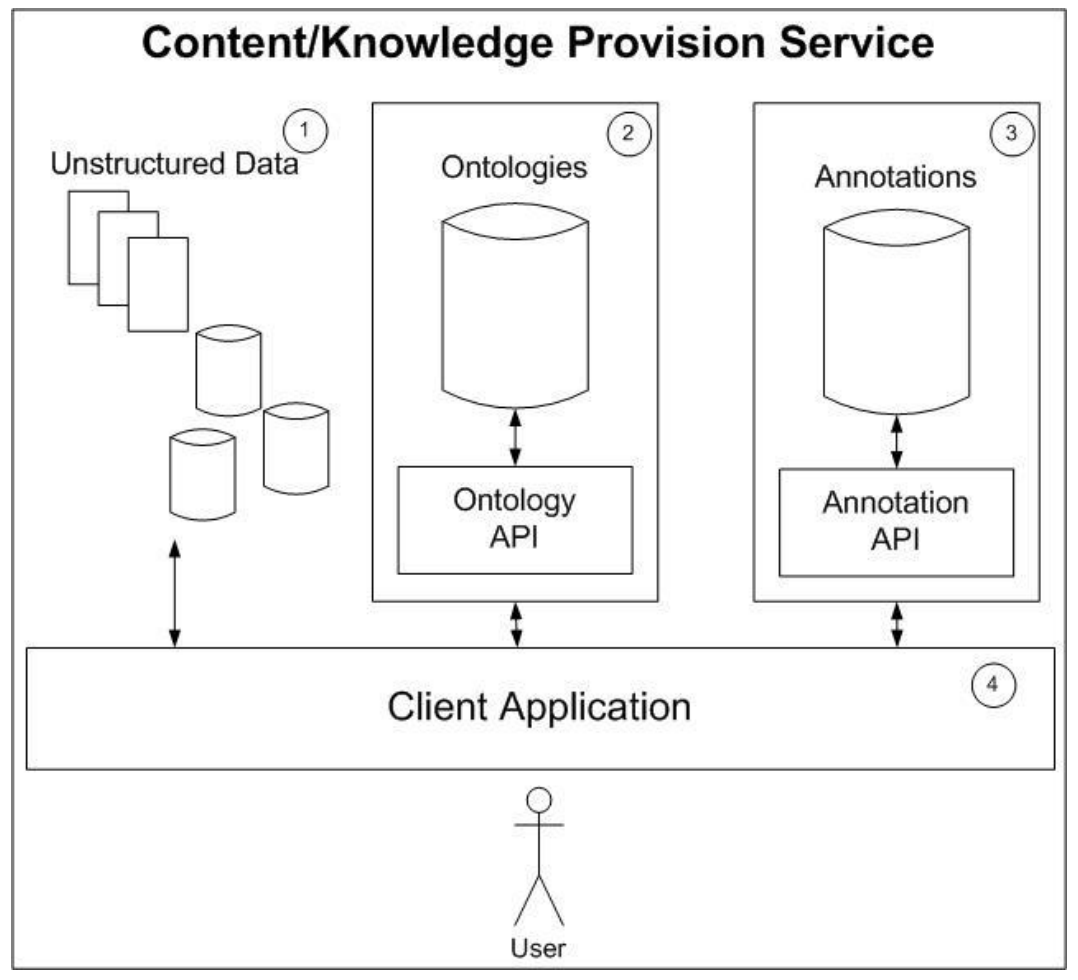

Figure 5. Context of the Content/Knowledge Provision service (based on Hebeler, et al., 2009)

The annotation of a specific source given the client application should know how to retrieve the source, how to query the annotation for further information about the source as well as how to render it to the learner.

The client application must also provide search and retrieval options, so the learner can request specific kinds of content or specific concepts associated with the content, regardless of their source.

The ontology management component enables the learner to access the ontologies that can be used to create and query annotations. It also enables selected users (i.e., domain experts) to incrementally build and extend domain ontologies as needed. Thus it directly communicates with IntelLEO ontology services (Jovanović et al., 2007) (not shown here explicitly). The ontologies used to annotate unstructured data sources should 
provide the learner (through the client application) with a set of relevant domain specific concepts and relationships (such as the concepts from the domain ontology).

The annotation management component provides access to existing annotations. This is the component that allows the client application to query the full set of annotations for those that meet a set of criteria/parameters. In order to query annotations efficiently, this component incorporates specialized indices that provide quick access to annotations that have specific characteristics. That way, this component enables efficient discovery, linking, and sharing of various document data across the relevant application, enterprise, and community boundaries. It introduces knowledge objects as open resources for employees according to defined organization policy, enabling querying, and containing data which is uniquely identified, semantically annotated and understandable by both humans and software agents.

The annotation management component of the Content/Knowledge Provision service is broken down into two pieces: the persistence mechanism and the access API. The access API is a client layer that provides the client application with a structured API for creating and retrieving annotations.

Annotations are RDF descriptions based on the Annotations ontology (specifically developed in the course of the IntelLEO project) and appropriate domain ontologies. Annotation instances have both general and specific contextual information associated with them. General information includes spatial and temporal descriptions, as well as the information necessary to index back into the unstructured source to which the annotation refers.

\subsection{Content/Knowledge Provision Framework}

To implement the Content/Knowledge Provision service, Semantic Web technologies (ontologies in particular), are used to describe formally the structure of KOs and bring formal semantics to the annotations.

Technically, the components of the Content/Knowledge Provision service are interconnected as it is shown in Figure 6. The basic interface components to enter or construct a query are text entry boxes restricted to match a value of a specific property. The interface for presenting query results is based on the faceted browsing technology (Hilderbrand et al., 2006). Faceted browsing allows the user to constrain the set of results within a particular facet. Typically, facets are directly mapped to properties in RDF. Alternatively, the mapping is made by projection rules. The advantage of an indirect mapping is that this allows the developer to define facets that match the user's needs while keeping the data structure unchanged.

The application logics of the whole Content/Knowledge Provision service is grouped into four logical parts: Management of knowledge objects, Annotation, Semantic search and Personalization. In the current implementation, it is only envisioned that the Content/Knowledge Provision Service should provide a certain level of personalization (Chirita, P., et. al, 2005), (Sieg, A. et. al, 2007) (e.g., in viewing/browsing knowledge objects, or in performing semantic search). However, this functionality is not implemented yet. 


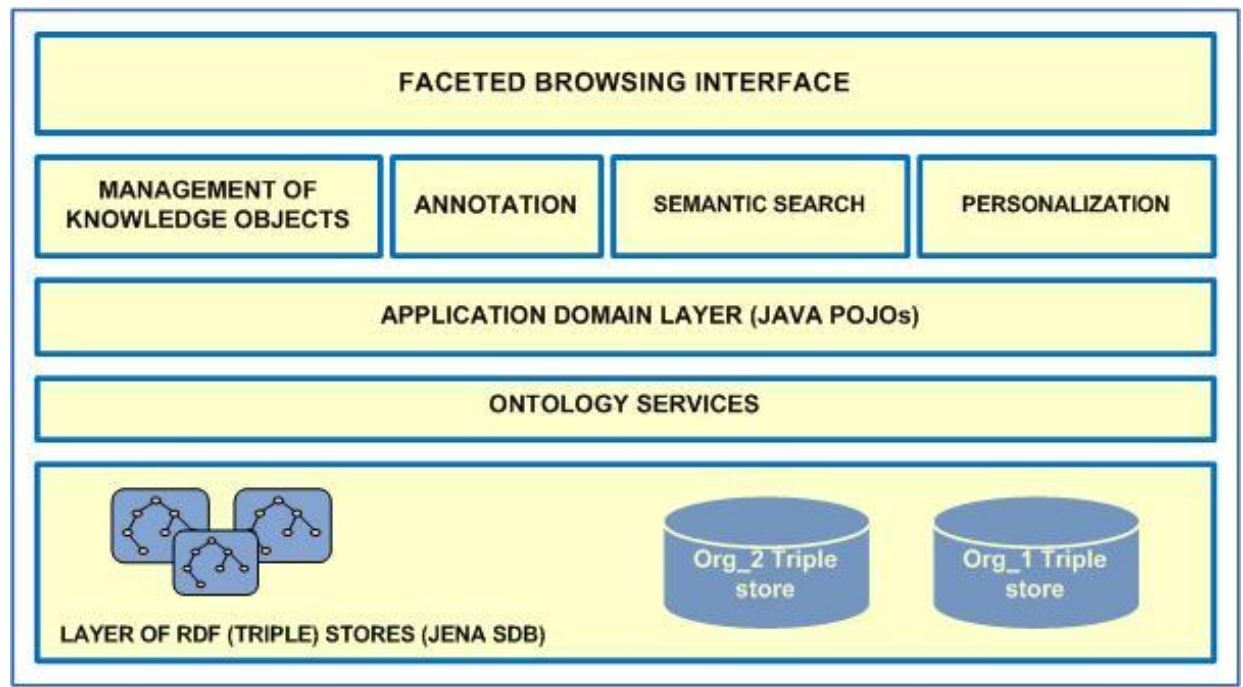

Figure 6. The layered architecture of the Content/Knowledge Provision service

\subsection{Management of Knowledge Objects}

Management of knowledge objects aims at creating/updating content and knowledge to be used later by IntelLEO learners in the process of achieving specific competencies related to their roles defined by the organization policy. This use case covers uploading a new KO into a knowledge base (e.g., into an RDF Repository), browsing/viewing the knowledge base, and deleting a $\mathrm{KO}$ from the knowledge base as shown in Figure 7. Uploading can be done only by the resource providers who are in charge of enriching the knowledge base with various knowledge objects. For example, in the INI / GOOD OLD AI application case resource providers are the researchers that find relevant resources on (INI) employee's specific domain or a trend of interest. The session starts after the user's authentication as the resource provider according the roles defined in the organization policy (however, checking the organization policy will be implemented only in the full prototype). The user can then upload a specific KO into the knowledge base as shown in Figure 8.

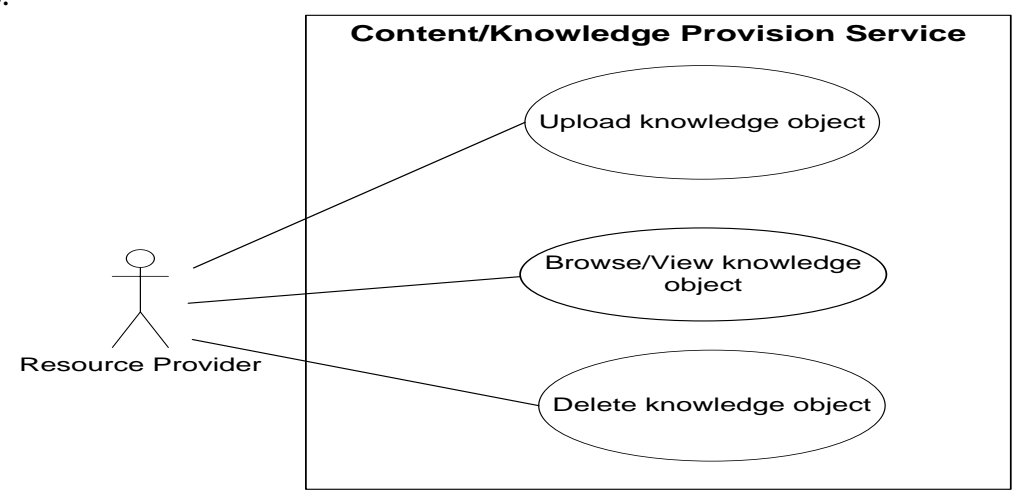

Figure 7. Management of the knowledge objects 


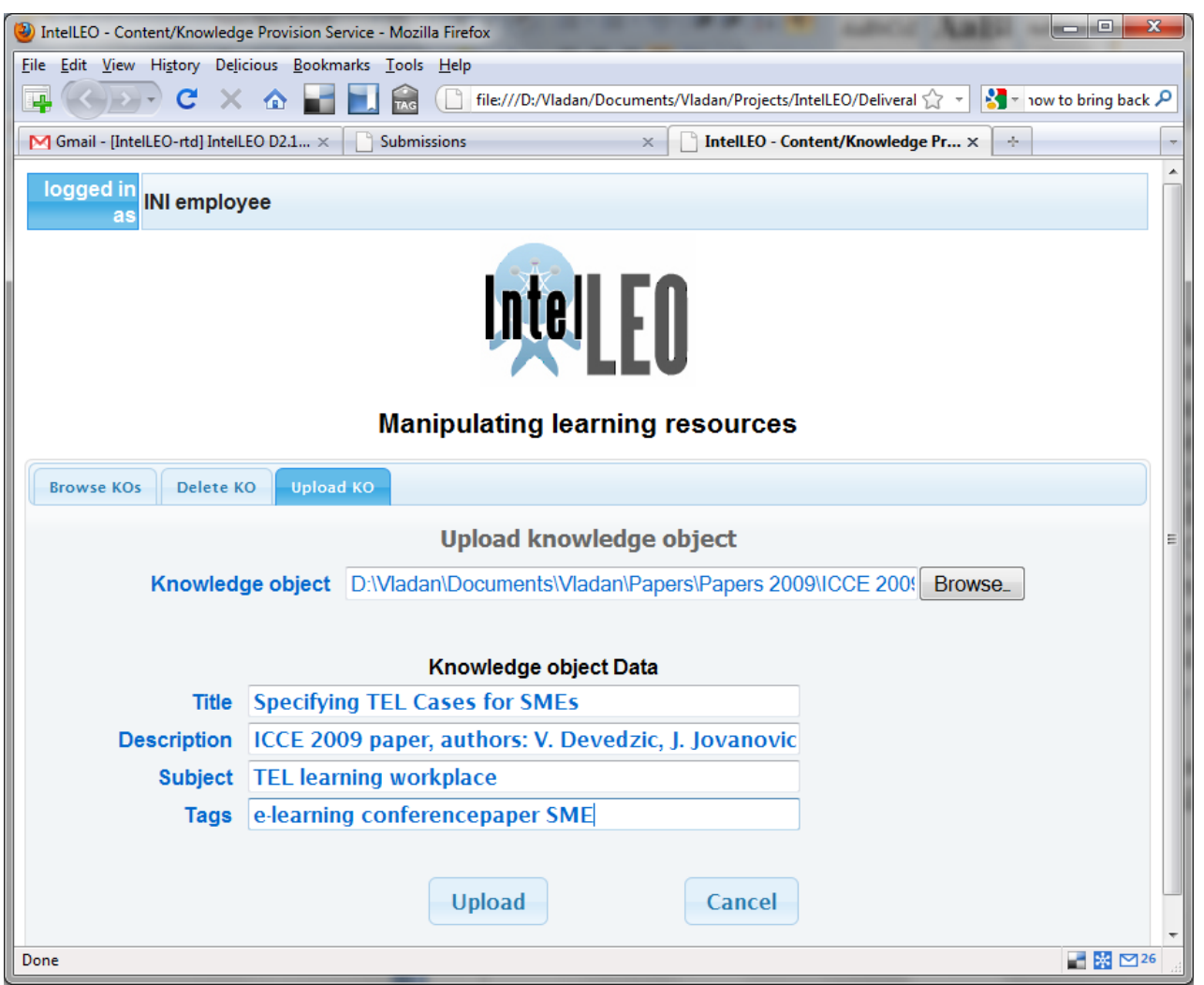

Figure 8. Uploading a knowledge object

\subsection{Annotation of knowledge objects}

Annotation of KOs refers to describing the uploaded knowledge objects with metadata, but without too much effort by the user/learner. There are three types of annotations as shown in Figure 9:

- description of knowledge objects with a basic set of descriptive metadata (based on the DC vocabulary);

- automatic annotation of knowledge objects with concepts from the domain ontology, which is often referred to as semantic annotation;

- tagging.

For describing knowledge objects during the upload there is the Annotations Ontology of the IntelLEO ontology framework (which makes use of the DC vocabulary). The most important information commonly used in this service is Title, Description, Subject, Terms. In some cases, this information can be extracted automatically; otherwise, the resource provider inputs this information manually during the process of uploading a knowledge object to the repository (see Figure 8).

Annotation of knowledge objects with concepts from the domain ontology is fully automated. It can be initiated by the resource provider. Users can annotate KOs with concepts from the domain ontology manually as well. 
Tagging is typically performed by learners during the learning process, but can be performed by resource providers as well.

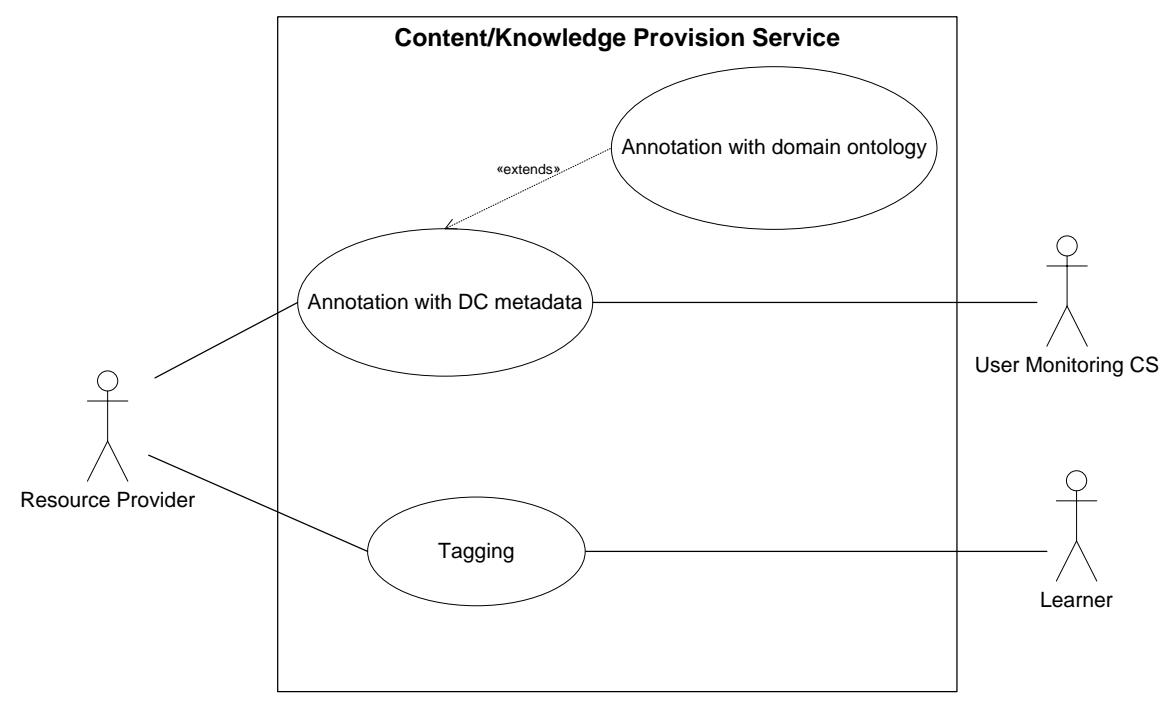

Figure 9. Annotation of knowledge objects

\subsection{Semantic search of knowledge objects}

Semantic search of knowledge objects assumes searching a knowledge base in order to find an appropriate knowledge object (Brut, M. et. al., 2009). Quick access to the relevant knowledge object(s) is essential here. The actors in this use-case can be a human user (such as a researcher or a learning-extended organization's employee) and one or more service components (such as the Learning Path Creator service).

Figure 10 shows some details of the semantic search of KOs. The Search configuration use case extends the Semantic search of knowledge objects in terms of specifying the search algorithm, the way the query is constructed, and the way the results should be presented.

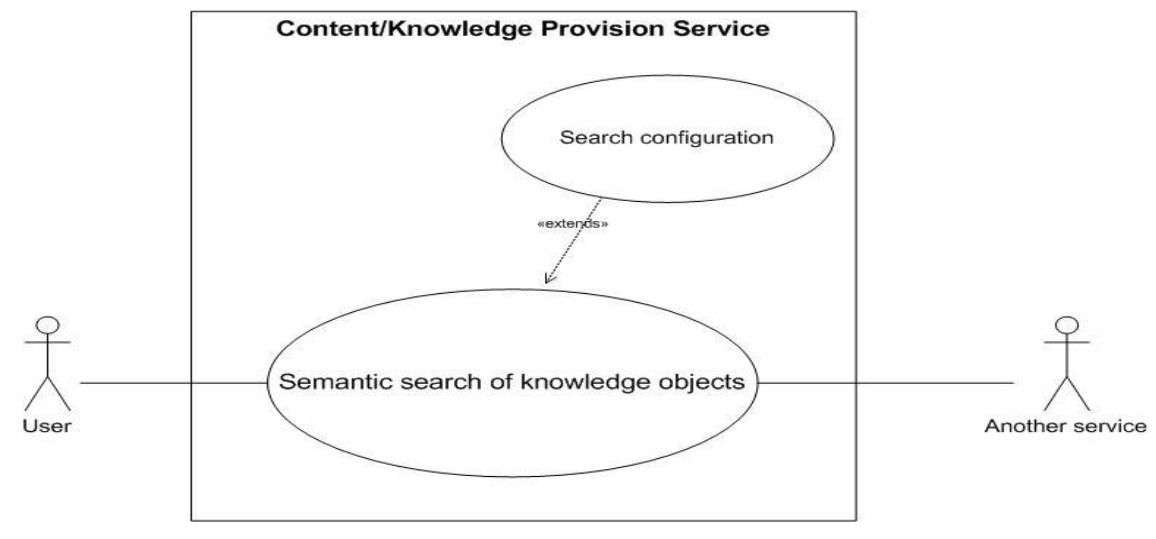

Figure 10. Semantic search of knowledge objects 
The order of the search results can be determined using different techniques. Ranking of results based on their relevance is one of well-covered topics in the field of information retrieval, and the Content/Knowledge Provision service follows that approach.

As an example scenario in which the actor in the Semantic search of knowledge objects is another service, consider the case when the Learning Path Creator service is used to recommend a learning path. This scenario includes two logical parts: searching for learning resources and generating recommendation.

In searching for learning resources, the Learning Path Creator (LPC) service offers the learner to select a competency he/she needs to acquire according to the role defined in the Organization Policy service. With respect to a specific competency, the learner has to perform one or more learning activities in order to finalize the process of achieving the competency. For each learning activity, there are one or more learning resources the learner has to use in order to master the activity.

After the learner selects a specific competency from the competency-tree, on-thefly assembly of the learning path begins. The LPC service defines the learning activities and activates the Content/Knowledge Provision service. This service then starts searching the knowledge objects repository for learning resources necessary to perform the first selected learning activity. This means that the Content/Knowledge Provision service, starting from the learner's initial query for the competency and already identified learning activities for achieving the specific competency, constructs the query to be sent to the repository of knowledge objects looking for the knowledge objects that match the query. If learning resources on the selected activity are not available, the LPC service informs the learner about it and suggests other suitable learning activities.

If found, the learning resources are ordered by a ranking algorithm. However, the current version of the Content/Knowledge Provision service not implement any specific ranking algorithm; only ordering by resource name and/or date of creation will be possible. Activities are underway to implement several ranking algorithms, thus making the Content/Knowledge Provision service more configurable.

\section{Discussion and Evaluation}

Remember that this way of identifying and presenting TEL cases for SMEs has resulted from a research project (IntelLEO). In spite of the fact that the presentation template shown in Figure 1 looks obvious and easy to devise, in practice it proved to be much more difficult to reach a consensus about it. The project participants are specialists with largely heterogeneous backgrounds, hence they initially had very different visions of how to present the project's three application cases. To make the things worse, even in a single field (such as software engineering, pedagogy, Web application development, and the like) there is now such a thing as a single, widely adopted, "standard" case presentation template. Thus a long debate among the project participants has preceded the adoption of the template shown in Figure 1.

Still, the template has proven to be a useful analysis and presentation tool for the project participants. Note that the three application cases of the IntelLEO project are very heterogeneous in their nature. However, all three were concisely and clearly described using the same template. The template is focused on the essential issues of an application - its TEL cases and their usage scenarios (see the proportions of the template sections in Figure 1 in terms of the respective numbers of pages). This sharpens the focus of the case 
presenter and leaves out details that would otherwise detach the reader's attention. Its style is also carefully selected to emphasize the organizational learning and knowledge management needs of the target organization, rather than diving into pure software analysis and design issues. Due to these features, the template and the overall TEL case identification and analysis approach used can be applied in other organizational learning projects as well.

\section{Conclusions}

The process of identifying and clearly describing TEL cases in organizational learning (Argyris and Schön, 1996) projects can be extremely difficult (Corrocher, and Fontana, 2008). There is no single widely adopted methodology that would be applicable successfully in all projects. Thus it is a essential for a well managed organizational learning project to adopt an effective approach early. In the IntelLEO project, an early decision on such an approach to identification and presentation of TEL cases, presented in this paper, has proven to be a useful requirements analysis tool. It is general enough to be useful in other projects related to TEL in organizations.

\section{Acknowledgments}

This publication was partially supported/co-funded by the European Community/European Union/EU under the Information and Communication Technologies (ICT) theme of the 7th Framework Program for R\&D (FP7). This document does not represent the opinion of the European Community, and the European Community is not responsible for any use that might be made of its content.

\section{References}

1 Allemang, D., \& Hendler, J. (2008). Semantic Web for the Working Ontologist: Effective Modeling in RDFS and OWL. Morgan Kaufmann

2 Argyris, C. \& Schön D.A (1996). Organizational Learning II. Addison-Wesley

3 Brut, M., Sedes, F., \& Zayani, C. (2009). Ontology-Based User Competencies Modeling for E-Learning Recommender Systems. In Collaborative and Social Information Retrieval and Access: Techniques for Improved User Modeling, Information Science Reference (an imprint of IGI Global), New York, 2009

4 Chirita, P. A., Nejdl, W., Paiu, R., \& Kohlsch utter, C. (2005). Using ODP metadata to personalize search. SIGIR '05: Proceedings of the 28th annual international ACM SIGIR conference on Research and development in information retrieval. ACM, Salvador, Brazil, 178-185.

5 Corrocher, N. \& Fontana, R., (2008). Expectations, network effects and timing of technology adoption: some empirical evidence from a sample of SMEs in Italy. Small Business Economics, Springer, vol. 31(4), 425-441.

6 Hebeler, J., Fisher, M., Blace, R., Perez-Lopez, A. \& Dean, M. (2009). Semantic Web Programming. Wiley Publishing, Inc., Indianapolis, Indiana. 
7 Hildebrand, M., van Ossenbruggen, J. \& Hardman L. (2006). facet: A browser for heterogeneous semantic web repositories. In I. Cruz et al. (eds.), Proceedings of ISWC 2006, volume 4273 of LNCS, 272-285.

8 Jovanović, J., Gašević, D., Knight, C., \& Richards G. (2007). Ontologies for Effective Use of Context in e-Learning Settings. Educational Technology \& Society, 10 (3), 47-59.

9 Sieg, A., Mobasher, B., \& Burke, R. (2007). Ontological User Profiles for Personalized Web Search. ITWP07: Proceedings of the Intelligent Techniques for Web Personalization Workshop, in the 22nd National Conference on Artificial Intelligence (AAAI 2007).

10 Stokić, D., Pata, K., Devedžić, V., Jovanović, J., Urošević, L., Gašević, D., Kieslinger, B. \& Wild, J. (2008). Intelligent Learning Extended Organizations. Proceedings of TELearn2008 (CD Edition), Hanoi, Vietnam.

11 Tuomi-Gröhn, T., \& Engeström, Y. (Eds.), (2003). Between School and Work: New Perspectives on Transfer and Boundary-Crossing. Amsterdam: Pergamon. 